Pesq. Vet. Bras. 36(2):67-72, fevereiro 2016 DOI: $10.1590 / \mathrm{S} 0100-736 \mathrm{X} 2016000200001$

\title{
Troponina C na detecção imuno-histoquímica de alterações regressivas precoces no miocárdio de bovinos e ovinos intoxicados por monofluoroacetato de sódio ${ }^{1}$
}

\author{
André M. Santos², Paulo V. Peixoto ${ }^{3}$, Mariana S. D’Ávila², Tiago C. Peixoto ${ }^{4}$, Ticiana \\ N. França ${ }^{5}$, Samay Z.R. Costa ${ }^{6}$, Gabriela C. Cid $^{2}$ e Vivian A. Nogueira ${ }^{5 *}$
}

\begin{abstract}
Santos A.M., Peixoto P.V., D’Ávila M.S., Peixoto T.C., França T.N., Costa S.Z.R., Cid G.C. \& Nogueira V.A. 2016. [Troponin C in immunohistochemical detection of early regressive myocardial lesions in cattle and sheep poisoned with sodium monofluoroacetate.] Troponina $C$ na detecção imuno-histoquímica de alterações regressivas precoces no miocárdio de bovinos e ovinos intoxicados por monofluoroacetato de sódio. Pesquisa Veterinária Brasileira 36(2):67-72. Departamento de Epidemiologia e Saúde Pública, Instituto de Veterinária, Universidade Federal Rural do Rio de Janeiro, Seropédica, RJ 23890-000, Brazil. E-mail: vivianmedvet@yahoo.com.br

Sodium monofluoroacetate (MF) is the toxic principle of several plants that cause "sudden death" of cattle in Brazil. Groups of cardiomyocites with high cytoplasmic eosinophilia are sometimes observed in animals poisoned by MF. However, this cardiac alteration is difficult to interpret, as there is no inflammatory reaction and it must be differentiated from artifacts. The present study had the objective to detect the presence of early regressive lesions in the myocardium of sheep and cattle experimentally poisoned by MF through immunohistochemistry with troponin C (cTnC). Fragments of the heart muscle from six cattle (three received, orally, single doses of $0.5 \mathrm{mg} / \mathrm{kg}$ and the others, single doses of $1.0 \mathrm{mg} /$ $\mathrm{kg}$ ) and five sheep (one received, orally, single dose of $0.5 \mathrm{mg} / \mathrm{kg}$, the other two received single doses of $1.0 \mathrm{mg} / \mathrm{kg}$, one received sublethal daily doses of $0.1 \mathrm{mg} / \mathrm{kg}$ for four days, and another received daily sublethal doses of $0.2 \mathrm{mg} / \mathrm{kg}$ for six days) were submitted to immunohistochemistry with antibody anti-cTnC. In the cardiomyocites of cattle and sheep, it was possible to observe reduction of the expression levels for cTnC in the cytoplasm of groups of cardiac muscle fibers. Significant reduction of immunoreactivity ocurred overall in cardiomyocites that presented high cytoplasmic eosinophilia. The decrease or absence of expression for cTnC in animals poisoned by MF allowed to estabilish the difference between coagulative necrosis of cardiomyocites and artifacts caused by fixation. This indicates that this method can be used safely to identify any lesions, early regressive or not, in the myocardium independently of the cause. It is also possible to affirm that poisoning by MF as well as the one caused by "sudden death" causing plants can progress with necrotizing myocardial lesions.
\end{abstract}

INDEX TERMS: Poisonous plants, monofluoroacetate, myocardial lesions, immunohistochemistry, troponin C, plant poisoning, cattle, sheep.

\footnotetext{
${ }^{1}$ Recebido em 29 de junho de 2015.

Aceito para publicação em 28 de novembro de 2015.

Parte da Dissertação de Mestrado do primeiro autor no Programa de Pós-Graduação em Medicina Veterinária, Universidade Federal Rural do Rio de Janeiro (UFRRJ), Seropédica, RJ 23890-000, Brasil.

${ }^{2}$ Programa de Pós-Graduação em Medicina Veterinária, UFRRJ, Seropédica, RJ 23890, Brasil.

${ }^{3}$ Departamento de Nutrição Animal e Pastagem, Instituto de Zootecnia, UFRRJ, Seropédica, RJ 23890-000, Brasil.
}

\footnotetext{
${ }^{4}$ Departamento de Anatomia, Patologia e Clínicas Veterinárias, Escola de Medicina Veterinária e Zootecnia, Universidade Federal da Bahia (UFBA), Avenida Adhemar de Barros 500, Bairro Ondina, Salvador, BA 40170-110, Brasil.

${ }^{5}$ Departamento de Epidemiologia e Saúde Pública, Instituto de Veterinária, UFRRJ, Seropédica, RJ 23890-000, Brasil. *Autor para correspondência: vivianmedvet@yahoo.com.br

${ }^{6}$ Programa de Pós-Graduação em Ciências Veterinárias, UFRRJ, Seropédica, RJ 23890-000, Brasil.
} 
RESUMO.- Ao que tudo indica, o monofluoroacetato de sódio (MF) é o princípio tóxico das numerosas plantas que causam "morte súbita" no Brasil. Eventualmente, observam-se, nos animais intoxicados por MF, grupos de cardiomiócitos com aumento da eosinofilia citoplasmática. Essas alterações cardíacas, no entanto, na maioria dos casos, ainda são incipientes, de difícil interpretação, não há reação inflamatória e devem ser diferenciadas de artefato. 0 presente trabalho teve como objetivo detectar a presença de alterações regressivas precoces no miocárdio de bovinos e ovinos intoxicados experimentalmente por MF, através da imuno-histoquímica com troponina C (cTnC). Fragmentos de coração de seis bovinos (três que receberam, por via oral, doses únicas de $0,5 \mathrm{mg} / \mathrm{kg}$ e, os demais, $1,0 \mathrm{mg} / \mathrm{kg}$ de MF) e cinco ovinos (um recebeu, por via oral, dose única de $0,5 \mathrm{mg} / \mathrm{kg}$, outros dois receberam doses de $1,0 \mathrm{mg} / \mathrm{kg} ; \mathrm{um}$ ovino recebeu, por via oral, doses subletais repetidas diariamente de $0,1 \mathrm{mg} / \mathrm{kg} /$ dia, por quatro dias, e outro, $0,2 \mathrm{mg} /$ $\mathrm{kg} /$ dia por seis dias) foram submetidos à técnica de imuno-histoquímica com anticorpo anti-cTnC. Nos cardiomiócitos dos bovinos e ovinos verificou-se redução dos níveis de expressão da cTnC no citoplasma de grupos de fibras musculares. Diminuição significativa na imunorreatividade ocorreu, sobretudo, em cardiomiócitos que apresentavam, no exame histopatológico, aumento da eosinofilia citoplasmática. A diminuição ou ausência da expressão da cTnC nos animais intoxicados por MF permitiu estabelecer a diferença entre necrose coagulativa de cardiomiócitos e artefato ocasionado pelo fixador. Isso indica que este método pode ser utilizado com segurança para identificação de lesões regressivas precoces, ou não, no miocárdio, independentemente da causa. Adicionalmente, é possível afirmar que, dependendo do tempo de evolução, a toxicose por MF, bem como por plantas causadoras de "morte súbita" em bovinos e ovinos, podem cursar com lesões necrotizantes no miocárdio.

TERMOS DE INDEXAÇÃO: Plantas tóxicas, monofluoroacetato, miocárdio, imuno-histoquímica, troponina C, intoxicação por plantas, bovinos, ovinos.

\section{INTRODUÇÃO}

O monofluoroacetato de sódio (MF), conhecido também como ácido monofluoroacético e composto 1080, é uma das substâncias mais tóxicas já descobertas (Zurita et al. 2007). Em bovinos (Schnautz 1949, Robison 1970, Nogueira et al. 2010, Peixoto et al. 2012) e ovinos (Jensen et al. 1948, Annison et al. 1960, Schultz et al. 1982, Peixoto et al. 2010), o principal efeito do MF se faz sobre o coração.

Ao que tudo indica, MF é o princípio tóxico das numerosas plantas que causam "morte súbita" no Brasil e são responsáveis por, pelo menos, 600.000 mortes de bovinos todos os anos. De fato, o quadro clínico-patológico verificado em ruminantes que ingerem essas plantas corresponde, em grande parte, ao observado nas intoxicações experimentais em bovinos e ovinos por MF (Tokarnia \& Döbereiner 1959, Nogueira et al. 2010, Peixoto et al. 2010, 2011, 2012). Em ambos os casos, a associação entre o quadro característico de morte súbita, ausência de achados de necropsia significativos e a típica degeneração hidrópico-vacuolar dos túbulos uriníferos contornados distais associada à cariopicnose TERMOS DE INDEXAÇÃO: Plantas tóxicas, monofluoroacetato, miocárdio, imuno-histoquímica, troponina $\mathrm{C}$, intoxicação por

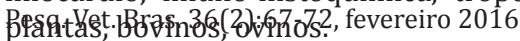

(DHV), presente na maioria dos casos, tem grande valor diagnóstico (Nogueira et al. 2010, Peixoto et al. 2010, 2011, Tokarnia et al. 2012). Ocorre que, quanto maior a dose ingerida de MF ou de plantas que o contêm, mais curto é o período para aparecimento dos sinais clínicos, isto é, animais que ingerem maiores quantidades do composto, morrem por parada cardíaca provavelmente antes que a eliminação da substância tenha causado a lesão renal significativa ou detectável ao exame histológico. Eventualmente, porém, observam-se, nos animais intoxicados por MF, grupos de cardiomiócitos com aumento da eosinofilia citoplasmática. Essas alterações cardíacas, no entanto, na maioria dos casos, ainda são incipientes, de difícil interpretação, não há reação inflamatória e devem ser diferenciadas de artefato resultante da hipercontração de miofibras ocasionada pelo fixador (Stigger et al. 2001).

Diversas técnicas imuno-histoquímicas com alta especificidade e sensibilidade têm sido empregadas no intuito de se detectar lesões incipientes no miocárdio. Dentre estas, destaca-se a utilização da troponina, um componente estrutural da célula muscular que é liberado na circulação cerca de 3 a 4 horas após a lesão celular (Aires et al. 1999, Jenkins et al. 2010). Os miócitos afetados apresentam uma marcação negativa, enquanto os miócitos não-necróticos são positivos para a troponina (Jenkins et al. 2010). Um estudo recente demonstrou que, em bovinos intoxicados de forma natural por Amorimia exotropica, planta tóxica cujo princípio tóxico é, provavelmente, o MF, há diminuição significativa na imunorreatividade anti-troponina cardíaca C (cTnC) em cardiomiócitos degenerados ou necróticos (Pavarini et al. 2012).

Dessa forma, esse estudo tem como intuito detectar a presença de alterações regressivas precoces no miocárdio de bovinos e ovinos intoxicados experimentalmente por MF, através da utilização imuno-histoquímica da cTnC, com o objetivo de auxiliar no diagnóstico histopatológico.

\section{MATERIAL E MÉTODOS}

Animais e amostras de tecidos. Foram utilizados fragmentos de coração, emblocados em parafina, de cinco ovinos e seis bovinos registrados no SAP (Setor de Anatomia Patológica), intoxicados previamente, por via oral, com monofluoroacetato de sódio - MF (Nogueira et al. 2010, Peixoto et al. 2010). Nestes estudos, três bovinos receberam doses únicas de $0,5 \mathrm{mg} / \mathrm{kg}$ e, os demais, $1,0 \mathrm{mg} / \mathrm{kg}$ de MF (Sigma-Aldrich $\mathrm{Co}^{\circledR}$ ). Um ovino recebeu dose única de $0,5 \mathrm{mg} / \mathrm{kg}$, outros dois, $1,0 \mathrm{mg} / \mathrm{kg}$, um animal foi intoxicado com doses subletais de $0,1 \mathrm{mg} / \mathrm{kg} / \mathrm{dia}$, por quatro dias, e outro, $0,2 \mathrm{mg} / \mathrm{kg} /$ dia por seis dias. Os bovinos e ovinos eram de ambos os sexos, raças e idades variadas. Para controle positivo, foram usados fragmentos de coração de um bovino intoxicado por Palicourea juruana e um ovino intoxicado de forma aguda por monensina e, para controle negativo, fragmentos cardíacos de um bovino e um ovino sem lesões aparentes e sem doença relacionada ao sistema cardiovascular.

Confecção das lâminas. Seções histológicas de $3 \mu \mathrm{m}$ dos corações dos bovinos e ovinos intoxicados, dos controles positivos e negativos para lesão cardíaca foram obtidas em cortes duplicados e de forma seriada, dos quais um foi destinado à coloração rotineira pela hematoxilina-eosina (HE) e outro em lâmina sinalizada para a técnica de imuno-histoquímica.

Imuno-histoquímica com anticorpo anti-cTnC. As seções histológicas foram desparafinadas em xilol, reidratadas em álcool 
e submersas em duas soluções de peróxido de hidrogênio a 3\% durante 15 minutos cada para bloqueio de peroxidases endógenas e então lavadas com tampão fosfato (PBS) por 2 minutos. Logo após, foram levadas ao banho-maria em solução de tampão citrato $(\mathrm{pH}=6)$, onde ficaram por 15 minutos à temperatura de $98^{\circ} \mathrm{C}$ para reativação dos sítios antigênicos. Para bloqueio de reações inespecíficas, foi utilizado leite desnatado por 30 minutos $\left(\right.$ Molico ${ }^{\circledR}$, Ind. Bras.). Os cortes foram incubados "overnight" com o anticorpo anti-cTnC (Novo Castra, clone 1A2) na diluição de 1:100. Após incubação, estes foram lavados com tampão fosfato e utilizaram-se os componentes Complemento (10 minutos) e Conjugado HRP (15 minutos) do kit Spring ${ }^{\circledR}$ REVEAL. As seções foram coradas com diaminobenzidina (DAB), contracoradas com hematoxilina de Harris e montadas para visualização em microscópio ótico.

Avaliação das lâminas. As lâminas foram avaliadas em microscópio óptico, sempre comparadas aos controles positivos e aos controles negativos. Para tal, também utilizamos o controle interno positivo e negativo, no qual os cardiomiócitos não lesados marcam positivamente para o anticorpo anti-cTnC e os demais tecidos que não expressam esta proteína são negativos (tecido conjuntivo, células inflamatórias e parede de grandes vasos).

Ao momento da avaliação microscópica (Nikon ${ }^{\circledR}$ Eclipse E200) e a partir da suspeita de aparecimento de áreas com hipereosinofilia de cardiomiócitos na coloração de HE, as seções submetidas ao exame imuno-histoquímico eram avaliadas em mesmo campo e com mesmo aumento e registradas através de fotomicrografia com câmera própria para microscópios (Moticam 25005.0 megapixels) e capturada pelo software Motic Cam 2.0.

A imunomarcação foi graduada como discreta, leve, moderada, acentuada ou muito acentuada.

\section{RESULTADOS}

\section{Análise comparativa dos resultados imuno-histoquí- micos e histopatológicos}

No Bovino 1 (1/6) havia pequena área com diminuição ou ausência de expressão para o anticorpo anti-cTnC, entremeada por células que apresentavam forte imunorreatividade. Essa área correspondia, no HE, a cardiomiócitos com perda da estriação e discreto aumento da eosinofilia. Nos demais bovinos (5/6) observaram-se extensas áreas em que os cadiomiócitos exibiam moderada a fraca imunorreatividade em meio a outros com forte imunorreatividade para o anticorpo anti-cTnC (Quadro 1). Essas áreas no H.E. demonstravam acentuada hipereosinofilia de grupos de miofibras ou de células isoladas (Fig.1 e 2). No Bovino 2 havia cistos de Sarcocystis spp. e pequenas áre-

Quadro 1. Resultados comparativos entre tempo de administração, evolução e achados histopatológicos na coloração de HE e IHQ em bovinos

\begin{tabular}{|c|c|c|c|c|c|}
\hline $\begin{array}{c}\text { Identificação } \\
\text { do Bovino } \\
\text { (Reg. SAP)* }^{*}\end{array}$ & $\begin{array}{l}\text { Dose única de MF } \\
\text { administrado } \\
\text { por VO }\end{array}$ & $\begin{array}{l}\text { Tempo desde a } \\
\text { administração à } \\
\text { apresentação } \\
\text { dos sintomas }\end{array}$ & Evolução clínica & $\begin{array}{l}\text { Achados histopatológicos } \\
\text { por HE }\end{array}$ & $\begin{array}{c}\text { Avaliação IHQ } \\
\text { com Anti-cTnC } \\
\text { (Marcação } \\
\text { negativa) }\end{array}$ \\
\hline Bov. 1 (31209) & $0,5 \mathrm{mg} / \mathrm{kg}$ & $2 \mathrm{~h}$ e $24 \mathrm{~min}$ & $12 \mathrm{~h}$ e $20 \mathrm{~min}$ & Hipereosinofilia de cardiomiocitos + & + \\
\hline Bov. 2 (31210) & $1,0 \mathrm{mg} / \mathrm{kg}$ & $3 \mathrm{~h}$ e $20 \mathrm{~min}$ & $5 \mathrm{~h}$ e $55 \mathrm{~min}$ & $\begin{array}{l}\text { Hipereosinofilia de cardiomiocitos ++ } \\
\text { Inflamação mononuclear + }\end{array}$ & ++ \\
\hline Bov. 3 (31211) & $0,5 \mathrm{mg} / \mathrm{kg}$ & 1h e $15 \mathrm{~min}$ & $3 \mathrm{~h}$ e $50 \mathrm{~min}$ & Hipereosinofilia de cardiomiocitos $++(+)$ & ++ \\
\hline Bov. 4 (31212) & $1,0 \mathrm{mg} / \mathrm{kg}$ & $2 \mathrm{~h}$ & $3 \mathrm{~h} \mathrm{e} 9 \mathrm{~min}$ & $\begin{array}{l}\text { Hipereosinofilia de cardiomiocitos ++ } \\
\text { Inflamação mononuclear + }\end{array}$ & ++ \\
\hline Bov. 5 (31213) & $0,5 \mathrm{mg} / \mathrm{kg}$ & $8 \mathrm{~h}$ e $35 \mathrm{~min}$ & $11 \mathrm{~h}$ e $24 \mathrm{~min}$ & $\begin{array}{c}\text { Hipereosinofilia de cardiomiocitos +++ } \\
\text { Cariólise }+ \\
\text { Inflamação mononuclear ++ }\end{array}$ & $++(+)$ \\
\hline Bov. 6 (31214) & $1,0 \mathrm{mg} / \mathrm{kg}$ & $3 \mathrm{~h}$ e $28 \mathrm{~min}$ & $1 \mathrm{~h}$ e $50 \mathrm{~min}$ & $\begin{array}{c}\text { Hipereosinofilia de cardiomiocitos }++(+) \\
\text { Picnose nuclear }+(+) \\
\text { Inflamação mononuclear }+\end{array}$ & +++ \\
\hline
\end{tabular}

* Reg. SAP = Número de Registro no Setor de Anatomia Patológica. MF = Monofluoroacetato de sódio, HE = Hematoxilina-Eosina, IHQ = Imuno-histoquímica. + Discreta, +(+) Leve, ++ Moderada, ++(+) Acentuada, +++ Muito acentuada.

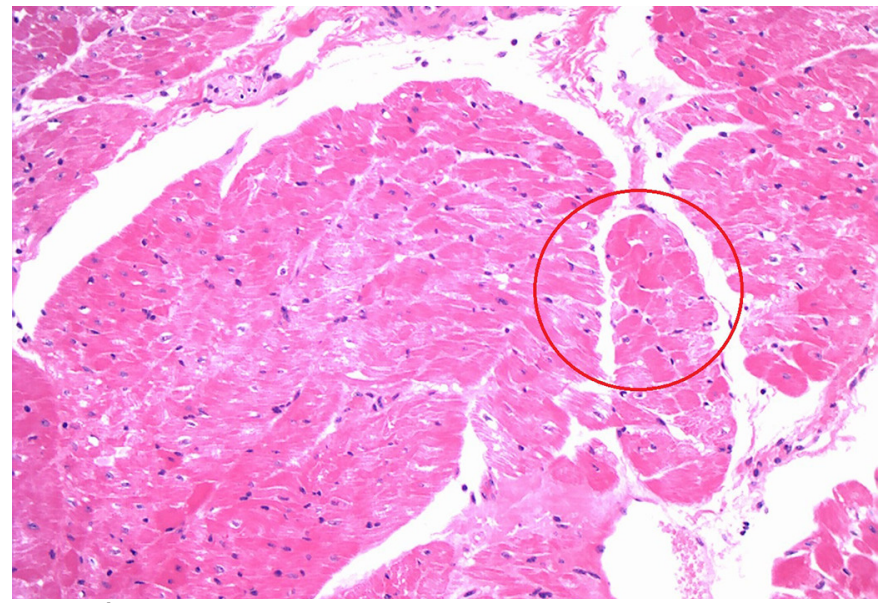

Fig.1. Áreas de hipereosinofilia de cardiomiócitos (no círculo). Bovino 31210 intoxicado por monofluoroacetato de sódio (1,0mg/kg). HE, obj.4x.

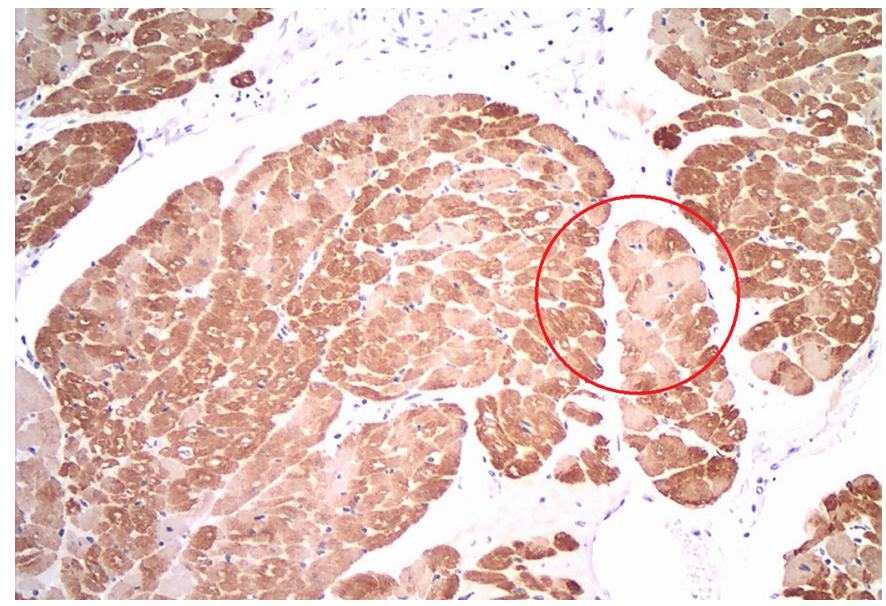

Fig.2. Diminuição da expressão para o anticorpo anti-cTnC (no círculo). Bovino 31210 intoxicado por monofluoroacetato de sódio $(1,0 \mathrm{mg} / \mathrm{kg})$. Obj.4x. 


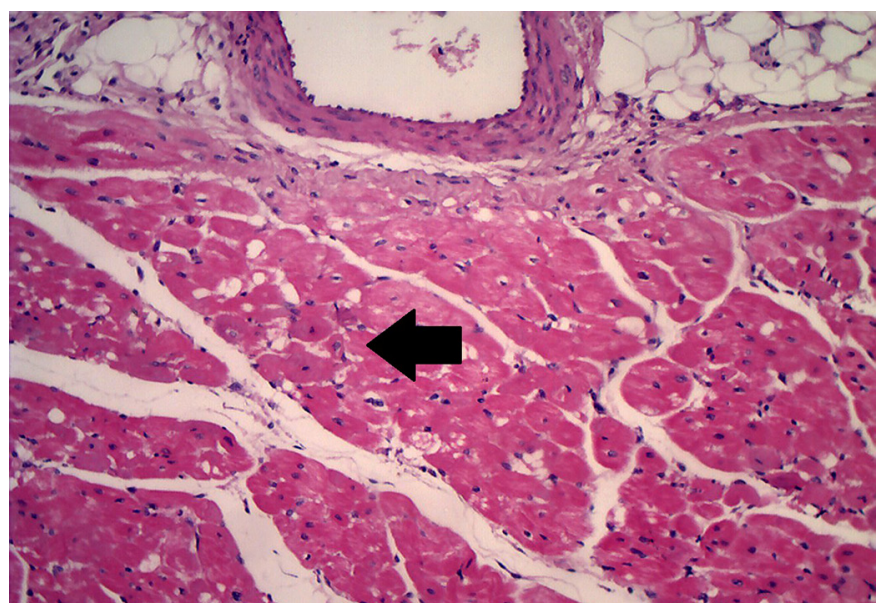

Fig.3. Áreas de hipereosinofilia com necrose e floculação de fibras musculares (seta). Ovino 31266 intoxicado por monofluoroacetato de sódio $(0,2 \mathrm{mg} / \mathrm{kg} /$ dia por 6 dias $)$. HE, obj.20x.

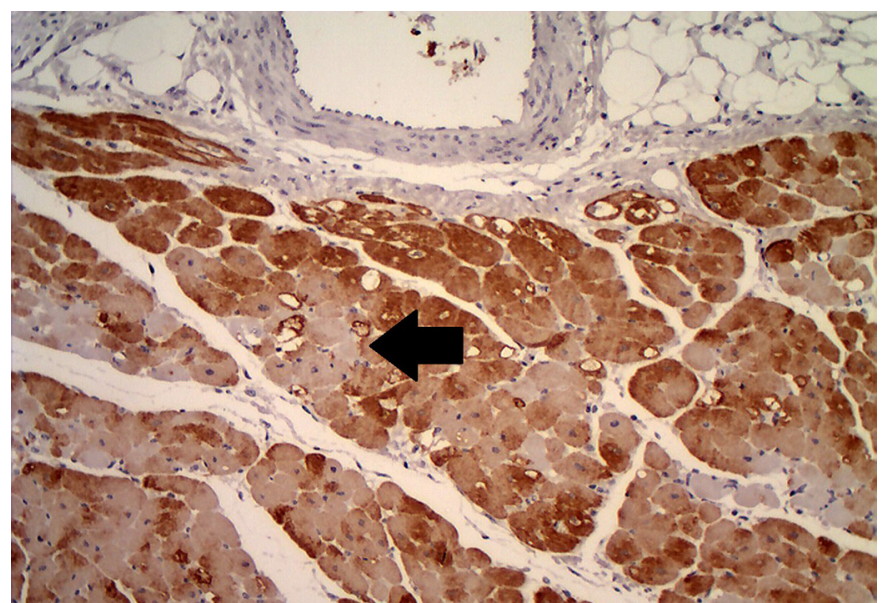

Fig.4. Acentuada perda de expressão para anticorpo anti-cTnC (seta). Ovino 31266 intoxicado por monofluoroacetato de sódio $(0,2 \mathrm{mg} / \mathrm{kg} /$ dia por 6 dias). Obj.20x.

Quadro 2. Resultados comparativos entre tempo de administração, evolução e achados histopatológicos na coloração de HE e IHQ em ovinos

\begin{tabular}{|c|c|c|c|c|c|}
\hline $\begin{array}{c}\text { Identificação } \\
\text { do Ovino } \\
\text { (Reg. SAP)* }\end{array}$ & $\begin{array}{c}\text { Dose única de MF } \\
\text { administrado } \\
\text { por VO } \\
\text { dos sintomas } \\
\end{array}$ & $\begin{array}{l}\text { Tempo desde a } \\
\text { administração à } \\
\text { apresentação }\end{array}$ & Evolução clínica & $\begin{array}{l}\text { Achados histopatológicos } \\
\text { por HE }\end{array}$ & $\begin{array}{c}\text { Avaliação IHQ } \\
\text { com Anti-cTnC } \\
\text { (Marcação } \\
\text { negativa) }\end{array}$ \\
\hline Ov. $1(31260)$ & $\begin{array}{l}0,5 \mathrm{mg} / \mathrm{kg} \text {, dose } \\
\text { única }\end{array}$ & $14 \mathrm{~h}$ e $6 \mathrm{~min}$ & $7 \mathrm{~h}$ e $55 \mathrm{~min}$ & $\begin{array}{l}\text { Hipereosinofilia de cardiomiocitos (+) } \\
\text { Inflamação mononuclear }+\end{array}$ & $++(+)$ \\
\hline Ov. 2 (31261) & $\begin{array}{l}\text { 1,0mg/kg, dose } \\
\text { única }\end{array}$ & $13 \mathrm{~h}$ e $20 \mathrm{~min}$ & 10 minutos & $\begin{array}{l}\text { Hipereosinofilia de cardiomiocitos }++(+) \\
\text { Inflamação mononuclear }+\end{array}$ & $++(+)$ \\
\hline Ov. 3 (31263) & $0,1 \mathrm{mg} / \mathrm{kg} / \mathrm{dia}$ & \multicolumn{2}{|c|}{$\begin{array}{l}\text { Encontrado morto sem } \\
\text { sinais de autólise }\end{array}$} & $\begin{array}{l}\text { Hipereosinofilia de cardiomiocitos ++ } \\
\text { Inflamação mononuclear + }\end{array}$ & $++(+)$ \\
\hline Ov. 4 (31265) & $\begin{array}{l}\text { 1,0mg/kg, dose } \\
\text { única }\end{array}$ & $9 \mathrm{~h}$ e $44 \mathrm{~min}$ & 3 minutos & Hipereosinofilia de cardiomiocitos $+(+)$ & ++ \\
\hline Ov. 5 (3) & $\begin{array}{l}0,2 \mathrm{mg} / \mathrm{kg} / \text { dia } \\
\text { durante } 4 \text { dias }\end{array}$ & $\begin{array}{l}3 \text { dias, } 16 \text { e e } 31 \\
\text { minutos após } \\
1^{\underline{a}} \text { adm }\end{array}$ & $33 \mathrm{~h}$ e 5 minutos & $\begin{array}{l}\text { Hipereosinofilia de cardiomiocitos +++ } \\
\text { Lise de cardiomiócitos ++ } \\
\text { Inflamação mononuclear ++ }\end{array}$ & +++ \\
\hline
\end{tabular}

* Reg. SAP = Número de Registro no Setor de Anatomia Patológica. MF = Monofluoroacetato de sódio, HE = Hematoxilina-Eosina, IHQ = Imuno-histoquímica. + Discreta, +(+) Leve, ++ Moderada, ++(+) Acentuada, +++ Muito acentuada.

as multifocais com leve infiltrado inflamatório linfohistioplasmocitário perivascular e ao redor de fibras de Purkinje. No bovino controle (intoxicado por Palicourea juruana) o exame histológico revelou acentuada necrose coagulativa de cardiomiócitos com perda de estriações e áreas de floculação das fibras, associada a marcado infiltrado inflamatório composto principalmente por macrófagos e, em menor número, linfócitos. Havia ainda moderada proliferação de tecido conjuntivo ao redor da área necrótica. Na imuno-histoquímica verificou-se acentuada perda de imunorreatividade para cTnC em grandes áreas da secção histológica, sobretudo ao redor de focos inflamatórios histiocitários.

Nos Ovinos 1, 2, 3 e 5 (4/5) verificaram-se extensos grupos de miofibras com marcada ausência de imunorreatividade que correspondiam no HE a áreas com hipereosinofilia acentuada de cardiomiócitos. Citoplasmólise de fibras musculares, associada a cariopicnose e cariólise eram observadas em diversos focos pela secções histológicas (Fig.3 e 4). Adicionalmente havia pequenos focos com moderado infiltrado inflamatório composto predominantemente por macrófagos que fagocitavam fibras necróticas. No Ovino 4 havia pequenos grupos de miócitos com moderada ausência de imunorreatividade (Quadro 2). Na coloração HE, essas áreas correspondentes demonstravam marcado aumento da eosinofilia de pequenos grupos de miócitos. No ovino controle (intoxicado por monensina), observou-se acentuada hipereosinofilia em diversos miócitos acompanhada de acentuado infiltrado inflamatório composto predominantemente por macrófagos e poucos linfócitos e plasmócitos. Picnose, carólise e citoplasmólise foram observados em alguns cardiomiócitos. $\mathrm{O}$ exame imuno-histoquímico revelou depleção na imunomarcação de fibras cardíacas, na qual algumas apresentavam fraca imunorreatividade em meio a outras com expressão normal para cTnC.

\section{DISCUSSÃO}

Nos cardiomiócitos de todos os bovinos e ovinos intoxicados por monofluoroacetato de sódio (MF), verificou-se redução dos níveis de expressão da cTnC no citoplasma de grupos de fibras musculares. Diminuição significativa na imunorreatividade ocorreu, sobretudo, em cardiomiócitos que apresentavam, no exame histopatológico, aumento da eosinofilia citoplasmática ou demais características histológicas de morte celular. Em diversos grupos de células 
havia completa perda de imunomarcação. Nos miócitos remanescentes e intactos dos animais intoxicados e daqueles utilizados como controle negativo, observou-se marcada imunorreatividade. A diminuição ou ausência da expressão de troponina cardíaca observada em todos os bovinos e ovinos desse estudo, indica variável grau de lesão de cardiomiócitos. Recentemente, lesões degenerativo-necróticas semelhantes foram demonstradas através da imuno-histoquímica para cTnC no coração de bovinos intoxicados por Amorimia exotropica (Pavarini et al. 2012, Bandinelli et al. 2014) e ovinos por Amaranthus spinosus (Costa et al. 2014). Além disso, estudos anteriores relatam o aumento da eosinofilia citoplasmática de fibras cardíacas em bovinos intoxicados por Mascagnia (Amorimia) sp. (Gava et al. 1998).

No homem, as troponinas são os marcadores bioquímicos mais sensíveis e específicos para detecção de lesão miocárdica (Wells \& Sleeper 2008). Dosagem sérica de troponina foi realizada em bovinos com lesões cardíacas, em casos de febre aftosa (Tunca et al. 2008, Karapinar 2010), endocardite valvular (Buczinski \& Bélanger 2010), pericardite (Mellanby et al. 2007), intoxicação por monensina (Varga et al. 2009) e infecção por Theileria annulata (Fartashvand et al. 2014). Em ovinos, a troponina sérica foi dosada em casos de arritmia cardíaca após intoxicação por salinomicina (Hajimohammadi et al. 2014) e lesão miocárdica em animais com acidose lática ruminal (Kirbas et al. 2014). Com relação à imuno-histoquímica, são escassos os trabalhos que relatam o uso do anticorpo anti-cTnC na detecção de alterações cardíacas em bovinos (Tunca et al. 2008, Pavarini et al. 2012) e ovinos (Costa et al. 2014). 0 anticorpo anticTnC humano é sensível para detectar lesões cardíacas em bovinos (Pavarini et al. 2012) e ovinos (Costa et al. 2014), o que sugere que os sítios antigênicos para estas proteínas são similares entre as espécies testadas.

As duas espécies apresentaram diferentes padrões na imunorreatividade com o anticorpo anti-cTnC, uma vez que, em bovinos, observou-se diminuição da expressão do anticorpo independente da dose do MF e do tempo de evolução. Por outro lado, em ovinos, a perda de expressão para cTnC estava relacionada com a dose da substância e a evolução clínica. Essas diferenças podem ter ocorrido pelo fato dos ovinos serem naturalmente menos sensíveis à intoxicação por MF e apresentarem, em média, evolução clínica mais prolongada em relação aos bovinos (Peixoto et al. 2010, Nogueira et al. 2011), mas também não se pode descartar o fato da expressão de cTnC não ocorrer de maneira uniforme por todo o miocárdio (Bandinelli et al. 2014).

Frequentemente eram vistos pequenos focos de infiltrado inflamatório linfoplasmocitário ao redor de vasos sanguíneos, sobretudo nos corações de bovinos. Estas alterações são comuns em decorrência de resposta imunológica à presença de cistos de Sarcocystis spp. em algumas seções histológicas (Lopes 2004). Entretanto, animais com lesões mais severas e visíveis na coloração H.E., apresentaram infiltrado inflamatório mononuclear em resposta à necrose coagulativa de cardiomiócitos, com floculação e fagocitose de fibras musculares. A imunomarcação de células inflamatórias foi observada por Tunca et al. (2008) em decor- rência da fagocitose de restos celulares de cardiomiócitos necróticos que podem conter traços das proteínas em seu interior. Tal fato não foi observado no nosso estudo, mesmo no Ovino 31266, intoxicado com doses subletais de $0,2 \mathrm{mg} /$ $\mathrm{kg} /$ dia durante 4 dias, que apresentou lesões degenerativo-necróticas no miocárdio.

O diagnóstico das intoxicações por MF em bovinos (Nogueira et al. 2010) e ovinos (Peixoto et al. 2010) e por plantas que possuem esta substância como princípio tóxico (Chenoweth \& Gilman 1946, Peixoto et al. 2010, Cook et al. 2014), se baseia na epidemiologia, associada à presença da planta no local e ao histórico de morte súbita. A típica DHV, quando presente, é de grande valor diagnóstico (Peixoto et al. 2010). Os achados de necropsia como ingurgitamento de vasos, edema e congestão pulmonares, hidropericárdio e edemas subserosos (Nogueira et al. 2010, Peixoto et al. 2010) corroboram a hipótese de que em ambos os casos pode haver lesão miocárdica concomitante com alterações funcionais do coração por déficit de ATP. A despeito disto, os achados histológicos, obtidos pela coloração rotineira (HE) no tecido cardíaco, não são considerados suficientes como forma diagnóstica para as intoxicações. No presente trabalho, a diminuição ou ausência da expressão da cTnC nos animais intoxicados por MF permitiu estabelecer a diferença entre necrose coagulativa de cardiomiócitos e artefatos. Isso indica que este método pode ser utilizado com segurança para identificação de quaisquer lesões regressivas precoces, ou não, no miocárdio, independentemente da causa. Adicionalmente, é possível afirmar que, dependendo do tempo de evolução, a toxicose por MF, bem como por plantas causadoras de morte súbita em bovinos e ovinos, podem cursar com lesões necrotizantes no miocárdio, como já descrito em casos de intoxicação por Fridericia (Pseudocalymma) elegans (Helayel et al. 2009), Palicourea aff. juruana (Palicourea juruana) (Tokarnia \& Döbereiner 1982) e Amorimia exotropica (Pavarini et al. 2012) em bovinos e Amorimia sepium em ovinos (Schons et al. 2011).

\section{CONCLUSÕES}

Detectaram-se alterações regressivas precoces no miocárdio de bovinos e ovinos intoxicados experimentalmente por monofluoroacetato de sódio (MF), através da utilização imuno-histoquímica do anticorpo anti-cTnC, o que torna o método uma valiosa ferramenta diagnóstica.

Agradecimentos.- À Coordenação de Aperfeiçoamento de Pessoal de Nível Superior (CAPES) e à Fundação de Amparo à Pesquisa do Estado do Rio de Janeiro (FAPERJ) pelo apoio financeiro para a pesquisa. Ao Dr. Jürgen Döbereiner pelas correções e traduções necessárias ao trabalho.

\section{REFERÊNCIAS}

Aires M.M. 1999. Regulação da excreção renal de eletrólitos e do volume do fluido extracelular, p.614-625. In: Ibid, (Ed.), Fisiologia. Guanabara Koogan, Rio de Janeiro. 934p.

Annison E.F., Hill K.J., Lindsay D.B. \& Peters R.A. 1960. Fluoroacetate poisoning in sheep. J. Comp. Pathol. 70:145-155.

Bandinelli M.B., Bassuino D.M., Fredo G., Mari C., Driemeier D., Sonne L. \& Pavarini S.P. 2014. Identificação e distribuição de lesões cardíacas em bovinos intoxicados por Amorimia exotropica. Pesq. Vet. Bras. 34(9):837-844. 
Buczinski S. \& Bélanger A. 2010. Bovine tricuspid endocarditis as a cause of increased serum concentration of cardiac troponins. Can. Vet. J. 51(2): 195.

Chenoweth M.B. \& Gilman A. 1946. Studies on the pharmacology of fluoroacetate. I. Species responses to fluoroacetate. J. Pharmacol. Exp. Therapeutics 87:90-103.

Costa S.Z.R., Peixoto P.V., D’avila M.S., Santos A.M., Nogueira V.A., Driemeier D., Brust L.A.C. \& França T.N. 2014. Troponina C na detecção de alterações regressivas precoces no miocárdio de ovinos intoxicados naturalmente por Amaranthus spinosus (Amaranthaceae). Anais VIII Encontro Nacional de Diagnóstico Veterinário (Endivet), Cuiabá, MT.

Cook D., Lee S.T., Taylor C.M., Bassüner B., Riet-Correa F., Pfister J.A. \& Gardner D.R. 2014. Detection of toxic monofluoroacetate in Palicourea species. Toxicon 80:9-16.

Fartashvand M., Nadalian M.G., Sakha M. \& Safi S. 2014. Elevated serum cardiac troponin I in cattle with theileriosis. J. Vet. Intern. Med. 27(1):194-199.

Hajimohammadi A., Rajaian H., Khaliji E., Nazifi S. \& Ansari-Lari M. 2014. Serum cardiac troponin I as a biomarker in cardiac degeneration following experimental salinomycin toxicosis in sheep. Veterinarski Arhiv 84(1):41-51.

Helayel M.A., França T.N., Seixas J.N., Nogueira V.A., Caldas S.A. \& Peixoto P.V. 2009. Morte súbita em bovinos causada pela ingestão de Pseudocalymma elegans (Bignoniaceae) no município de Rio Bonito, RJ. Pesq. Vet. Bras. 29(7):498-508.

Gava A., Cristani J., Branco J.V., Neves D.S., Mondadori A.J. \& Souza R.S. 1998. Mortes súbitas em bovinos causadas pela ingestão de Mascagnia sp. (Malpighiaceae), no Estado de Santa Catarina. Pesq. Vet. Bras. 18(1):16-20.

Jenkins C.P., Cardona D.M., Bowers J.N., Oliai B.R., Allan R.W. \& Normann S.J. 2010. The utility of C4d, C9, and troponin T immunohistochemistry in acute myocardial infarction. Archs Pathol. Lab. Med. 134:256-263.

Jensen R., Tobiska J.W. \& Ward J.C. 1948. Sodium fluoroacetate (Compound 1080) poisoning in sheep. Am. J. Vet. Res. 9:370-372.

Kirbas A., Baydar E., Kandemir F.M., Dorman E., Kizil O. \& Yildirim B.A. 2014. Evaluation of serum cardiac troponin I concentration in sheep with acute ruminal lactic acidosis. Veterinarski Arhiv 84(4):355-364.

Karapinar T., Dabak D.O., Kuloglu T. \& Bulut H. 2010. High cardiac troponin I plasma concentration in a calf with myocarditis. Can. Vet. J. 51(4):397.

Lopes C.W.G. 2004. 0 gênero Sarcocystis (Lankester, 1882) (Apicomplexa: Sarcocystidae), uma questão a ser reavaliada no Brasil. Revta Bras. Parasitol. Vet. 13(Supl.1):14-16.

Mellanby R.J., Henry J.P., Cash R., Ricketts S.W., Dias Bexiga J.R. \& Mellor D.J. 2007. Serum cardiac troponin I concentration in cattle with pericarditis. Vet. Rec. 161:455-456.

Nogueira V.A., França T.N., Peixoto T.C., Caldas S.A., Armién A.G. \& Peixoto P.V. 2010. Intoxicação experimental por monofluoroacetato de sódio em bovinos: aspectos clínicos e patológicos. Pesq. Vet. Bras. 30(7):533-540.

Nogueira V.A., Peixoto T.C., França T.N., Caldas S.A. \& Peixoto P.V. 2011. Intoxicação por monofluoroacetato em animais. Pesq. Vet. Bras. 31(10):823838.
Pavarini S.P., Bandinelli M.B., Juffo G.D., Souza S.O., Driemeier D. \& Cruz C.E.F. 2012. Decreased expression of cardiac troponin C is associated with cardiac lesions in Amorimia exotropica poisoned cattle. Pesq. Vet. Bras. 32(10):1005-1008.

Peixoto T.C., Nogueira V.A., Coelho C.D., Veiga C.C.P., Peixoto P.V. \& Brito M.F. 2010. Aspectos clínico-patológicos e laboratoriais da intoxicação experimental por monofluoroacetato de sódio em ovinos. Pesq. Vet. Bras. 30(12):1021-1030.

Peixoto P.V., Nogueira V.A., França T.N., Peixoto T.C., Döbereiner J. \& Tokarnia C.H. 2011. Relationship between a peculiar form of hydropic-vacuolar degeneration of the distal convoluted tubules, monofluoroacetate poisoning, and plants that cause "sudden death" in Brazil, p.365-372. In: Riet-Correa F., Pfister J., Schild A.L. \& Wierenga T. (Eds), Poisoning by Plants, Mycotoxins, and Related Toxins. CABI, London.

Peixoto T.C., Nogueira V.A., Caldas S.A., França T.N., Anjos B.L., Aragão A.P. \& Peixoto P.V. 2012. Efeito protetor da acetamida em bovinos indica monofluoroacetato como princípio tóxico de Palicourea marcgravii (Rubiaceae). Pesq. Vet. Bras. 32(4):319-328.

Robison W.H. 1970. Acute toxicity of sodium monofluroacetate to cattle. J. Wildl. Managmt. 34:647-648.

Schnautz J.0. 1949. Sodium fluoroacetate (Compound 1080) poisoning in cattle. J. Am. Vet. Med. Assoc. 114(864):435.

Schons S.V., De Mello T.L., Riet-Correa F. \& Schild A.L. 2011. Poisoning by Amorimia (Mascagnia) sepium in sheep in northern Brazil. Toxicon 57(5):781-786.

Schultz R.A., Coetzer J.A.W., Kellerman T.S. \& Naudé T.W. 1982. Observations on the clinical, cardiac and histopathological effects of fluoracetate in sheep. Onderstepoort J. Vet. Res. 49:237-245.

Stigger A.L., Barros C.S.L., Langohr I.M. \& Barros S.S. 2001. Intoxicação experimental por Ateleia glazioviana (Leg.Papilionoideae) em ovinos. Pesq. Vet. Bras. 21(3):98-108.

Tokarnia C.H. \& Döbereiner J. 1959. Intoxicação de bovinos pela "erva de rato" (Palicourea marcgravii St Hil.) no vale do Itapicurú, Maranhão. Arqs Inst. Biol. Anim., Rio de J., 2:83-91.

Tokarnia C.H., Brito M.F., Barbosa J.D., Peixoto P.V. \& Döbereiner J. 2012. Plantas Tóxicas do Brasil. 2ª ed. Editora Helianthus, Rio de Janeiro. 586p.

Tokarnia C.H. \& Döbereiner J. 1982. Intoxicação experimental por Palicourea juruana (Rubiaceae) em bovinos e coelhos. Pesq. Vet. Bras. 2(1):1726.

Tunca R., Sozmen M., Erdogan H., Citil M., Uzlu E., Ozen H. \& Gokçe E. 2008. Determination of cardiac troponin I in the blood and heart of calves with foot-and-mouth disease. J. Vet. Diagn. Invest. 20(5):598-605.

Varga A., Schober K.E., Holloman C.H., Stromberg P.C., Lakritz J. \& Rings D. M. 2009. Correlation of Serum Cardiac Troponin I and Myocardial damage in Cattle with Monensin Toxicosis. J. Vet. Intern. Med. 23:1108-1116.

Wells S.M. \& Sleeper M. 2008. Cardiac troponins. J. Vet. Emerg. Critic. Care 18(3):235-245.

Zurita J.L., Jos A., Cameán A.M., Salguero M., López-Artíguez M. \& Repetto G. 2007. Ecotoxicological evaluation of sodium fluoroacetate on aquatic organisms and investigation of the effects on two fish cell lines. Chemosphere 67:1-12. 